\title{
Decades of Work to Reduce Disparities in Health Care Produce Limited Success
}

Rebecca Voelker

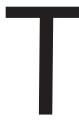

HE EARLY WEEKS OF 2008 BROUGHT discouraging news for advocates working to narrow health care disparities among racial and ethnic groups. In rapid succession, several studies published in January in peer-reviewed journals showed that despite decades of efforts to raise awareness about disparities and to reduce them, the gaps in some key treatment areas have not budged.

The latest findings build on years of research that has established the extent of inequalities in treatment for cancer, heart disease, diabetes, and many other conditions. Cancer, for example, has been the focus of dozens of studies and a number of federal initiatives to document and reduce treatment disparities. However, a new analysis of 143512 Medicare patients with breast, colorectal, lung, and prostate cancers shows that from 1992 to 2002, not only did treatment disparities persist, the magnitude of the disparities did not diminish (Gross CP et al. Cancer. 2008;112[4]:900-908).

A number of studies also have documented racial and ethnic disparities in pain control, and several initiatives have sought to improve the overall quality of pain management. But even though prescriptions for pain-relieving opioid drugs rose by $60 \%$ in emergency departments from 1993 to 2005 following campaigns to improve pain control, minority patients did not receive these drugs as often as white patients. In 2005 , opioid prescriptions were $8 \%$ higher in white patients in the emergency department than in minority patients (Pletcher MJ et al. JAMA. 2008; 299[1]:70-78).
With greater awareness directed toward the issue through such majorreports as the Institute of Medicine's Unequal Treatment: Confronting Racial and Ethnic Disparities in Health Care, published in 2003, the body of data on health care disparities is expanding. For example, a study examining treatment of adults with extremity soft-tissue sarcomas showed that blacks had the lowest rates of limbpreserving surgeries and the highest rates of amputations in comparison with white, Hispanic, and Asian patients. Blacks also had the lowest rates of radiation therapy used in conjunction with surgery, and when researchers controlled for factors including age, sex, tumor size, and tumor grade, black patients were 23\% less likely than whites to receive radiation and sur- gery. (Martinez SR, et al. Cancer. 2008; 112[5]1162-1168).

\section{OUTRAGED BUT NOT SURPRISED}

The apparent lack of progress in reducing health care disparities is more than frustrating for many experts in the field. "We should be outraged by these findings," says Ernie Moy, MD, medical officer at the federal Agency for Healthcare Research and Quality (AHRQ). However, he adds, "We should not be surprised."

Taking a historical view, Moy says that racial and ethnic health disparities in the United States are as old as the country itself. That point is made in Unequal Treatment, which explains that blacks, American Indians, and low-income populations were the least healthy and had the poor-
Change in disparities in core quality measures over time for members of selected groups compared with reference group from 2000-2001 to 2004-2005a

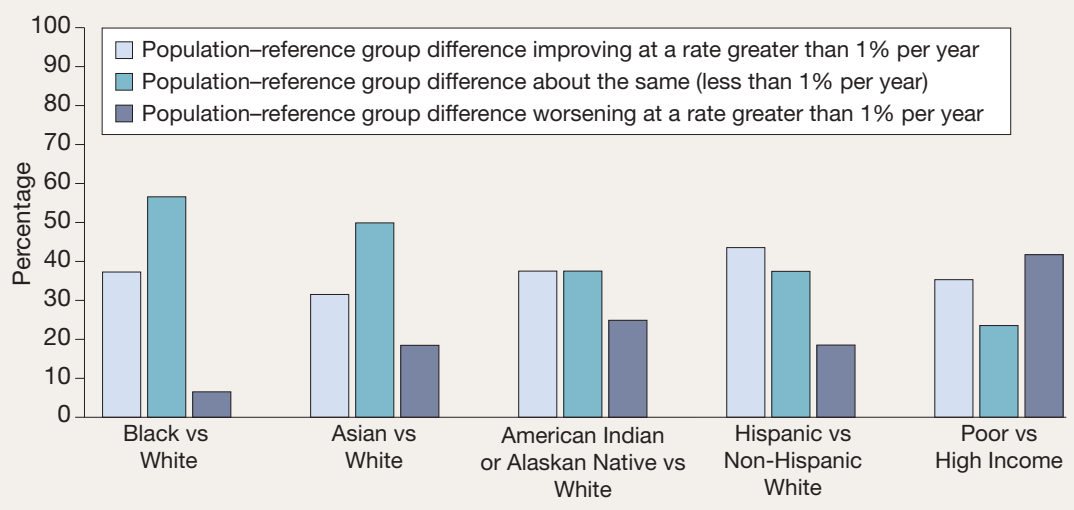

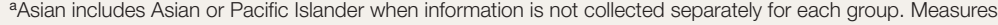
presented here for racial and ethnic minority groups are a subset of the core measures set that has data for all groups. Some measures for the poor are different from the measures used for racial and ethnic groups.

Source: Agency for Healthcare Research and Quality. 2008. National Healthcare Disparities Report. 2007. Rockville, MD: US Department of Health and Human Services, Agency for Healthcare Research and Quality; February 2008. AHRQ Publication No. 08-0041. Accessed March 6, 2008. http://www.ahrq.gov/qual/qrdr07.htm

One way in which the National Healthcare Disparities Report examines disparities is by tracking core quality measures such as mammography rates. The 2007 report shows that for 16 core measures, more than $50 \%$ of disparities in quality care have not gotten smaller. 
est health care and outcomes even before the Revolutionary War.

Modern efforts to tackle racial and ethnic health disparities include a landmark 1985 federal report on variations in health status among nonwhite populations, issued by the US Department of Health and Human Services and its former head, Margaret Heckler. A year later, the Office of Minority Health, the first federal agency devoted to minority health status and treatment, was created.

In 1999 Congress directed the AHRQ to begin compiling an annual analysis, the National Healthcare Disparities Report, as part of a nationwide effort to eliminate health care disparities. The recently released 2007 report found that disparities in health care quality have not improved since the agency released its first report in 2003. For blacks, Hispanics, American Indians or Alaska Natives, Asians, and the poor, measures of disparities that worsened significantly or remained the same outnumbered those that improved significantly.

Examples cited in the 2007 AHRQ report show that compared with whites, blacks had significantly more new AIDS cases and pediatric asthma hospitalizations, American Indian and Alaska Native women were less likely to receive prenatal care, and Asian women had significantly lower rates of mammography. Compared with high-income individuals, the poor had more difficulty getting care for an immediate illness or injury.

"We still have disparities; progress has been very, very limited," says Moy.

\section{NO EASY ANSWERS}

But after numerous reports and scientific studies that document disparities and decades of efforts by public and private initiatives, why is it that headway in reducing disparities appears to be mired in quicksand?

The reasons for disparities mostly involve 3 categories of "patient factors, provider factors, and health system factors," says Marsha Lillie-Blanton, DrPH, senior advisor on race, ethnicity, and health care at the Henry J. Kaiser Family Foundation, which is headquartered in Menlo Park, Calif. "Oftentimes," says Lillie-Blanton, "our interventions tend to focus on just one of these. But multiple factors have to be addressed, and that is not easy in a system that is very complex and has many intertwining factors."

Numerous initiatives to improve the overall quality of care have been started in the United States during the last decade or two, but Moy says that while they may have improved quality in some areas, they did not specifically address disparity reduction.

"When we improve quality for everybody, we see 2 lines of improvement," he explains. "The majority population is getting better, the minority population is getting better, and if those lines are parallel, it just means you've continued the disparities. There's been relatively little activity that has focused specifically on disparities."

Inherent within health disparities are socioeconomic issues that are beyond the scope of physicians and the health care system. Cary Gross, MD, an associate professor of medicine at the Yale University School of Medicine in New Haven, Conn, is lead author of the study that showed no reduction in disparities in cancer care for Medicare patients from 1992 to 2002. Even in this insured population, disparities persisted. Gross says disparities reflect the complex social structure of the United States.

"We need to consider not only factors such as health insurance and patient education, which are critical, but also more challenging concepts such as profound inequities in socioeconomic status and distrust of the health care system by members of vulnerable populations," says Gross.

A past president of the National Medical Association says that some of the studies documenting racial and ethnic health disparities illustrate the need for new attitudes toward minority patients. Sandra Gadson, MD, who also co-chairs the Commission to End
Health Care Disparities (CEHCD) with the American Medical Association's President Ronald Davis, MD, is particularly troubled by the recent findings on opioid use in emergency departments.

"There is a definite difference in how those drugs are being used, and that speaks to stereotypes," explains Gadson. "There are preconceived ideas that [minority patients] are not actually having this pain or they are not being truthful."

The CEHCD, which formed in 2004 and comprises more than 60 health organizations, is taking a number of steps to help reduce or eliminate disparities. These include a goal of trying to reach 100000 minority students in middle and high schools to encourage them to choose medical careers and thus boost diversity in the health care workforce. Another initiative is aimed at reducing the sodium content of processed foods to help lower rates of hypertension, which disproportionately affects blacks. Also, the commission is working with pharmaceutical companies to produce culturally sensitive materials about the importance of taking medications according to physicians' instructions and how to follow-up with a physician or pharmacist if medication questions arise.

\section{ISOLATED IMPROVEMENT}

Although studies documenting disparities are not in short supply, findings about what works to reduce disparities are. A 3-year, \$6-million program called Finding Answers: Disparities Research for Change, sponsored by the Robert Wood Johnson Foundation, seeks to identify effective interventions to eliminate disparities.

Under the direction of Marshall Chin, $\mathrm{MD}, \mathrm{MPH}$, an associate professor of medicine at the University of Chicago Pritzker School of Medicine, the program reviewed more than 200 journal articles on disparity reduction interventions in cardiovascular disease, depression, diabetes, and breast cancer. The results appeared in October 2007 
in a supplement to Medical Care Research and Review.

One of the few studies in the review that showed a reduction in racial disparities was part of the Racial and Ethnic Approaches to Community Health (REACH 2010) program, sponsored by the US Centers for Disease Control and Prevention in Atlanta, Ga. The demonstration program, which took place in Charleston and Georgetown counties in South Carolina, brought together 28 community partners, from health professionals to college sororities and local media, that set goals to improve diabetes care for blacks as well as eliminate health care disparities between black and white patients with diabetes.

The partners documented disparities in care for 12000 black patients with diabetes in the 2-county community. The intervention included such community activities as health fairs, support groups, grocery store tours, community clinics, and church-based educational programs. After 24 months, the partners audited medical charts for 158 black patients and 112 patients who were white or of other racial or ethnic groups. They found that differences between black and white patients in rates of hemoglobin $\mathrm{A}_{1 \mathrm{c}}$ testing, lipid and kidney testing, eye examinations, and blood pressure control that had ranged from $11 \%$ to $28 \%$ at baseline had been eliminated (Jenkins C et al. Public Health Rep. 2004;119[3]:322-330).

Chin is optimistic that other communities will develop their own, similar programs in the future. "There are a lot of promising models," he says. "But you may have to revise as you go along, just like in patient care."

\section{Contradictory Findings Ignite Questions About Blood Glucose Targets in Diabetes}

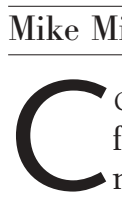

Mike Mitka

ONFLICTING CLINICAL TRIAL findings announced through nity wondering about the possible dangers of aggressively lowering blood glucose below the levels recommended in current guidelines.

At issue is the February 6 announcement and statement by the National Heart, Lung, and Blood Institute (NHLBI) that it was stopping an arm of the Action to Control Cardiovascular Risk in Diabetes (ACCORD) study involving intensive treatment aimed at lowering blood glucose to reach a glycated hemoglobin $\mathrm{A}_{\mathrm{lc}}\left(\mathrm{HbA}_{\mathrm{lc}}\right)$ goal of less than $6 \%$. Current guidelines from the American Diabetes Association (ADA) set the desired $\mathrm{HbA}_{\mathrm{lc}}$ level at $7 \%$ or below. The stoppage came at the recommendation of a 10-member data and safety monitoring board that detected an unexpected higher mortality rate in patients randomized to the aggressively treated group compared with those randomized to the standard treatment group (http://www.nhlbi .nih.gov/health/prof/heart/other/accord /index.htm).
The NHLBI action prompted a press release a week later from the industrysponsored Action in Diabetes and Vascular Disease (ADVANCE) trial, stating that interim results from ADVANCE showed no evidence of increased mortality risk for patients receiving intensive treatment to lower blood glucose levels (http://www.advance-trial.com/static /html/virtual/contents.asp?P=39).

For physicians treating patients with diabetes, the way these findings were conveyed-through press conferences and news releases rather than through peer-reviewed journals or pre- sentations at major scientific meetings-has left them uncertain of the implications for their treatment strategies.

"My guess is that in endocrinology offices around the world, this is the water-cooler discussion," said Irl B. Hirsch, MD, a professor of medicine at the University of Washington Medical CenterRoosevelt in Seattle and a participant in the ACCORD study.

\section{OPPOSING RESULTS}

The ACCORD study enrolled 10251 people with type 2 diabetes at 77 sites in the United States and Canada. Par-

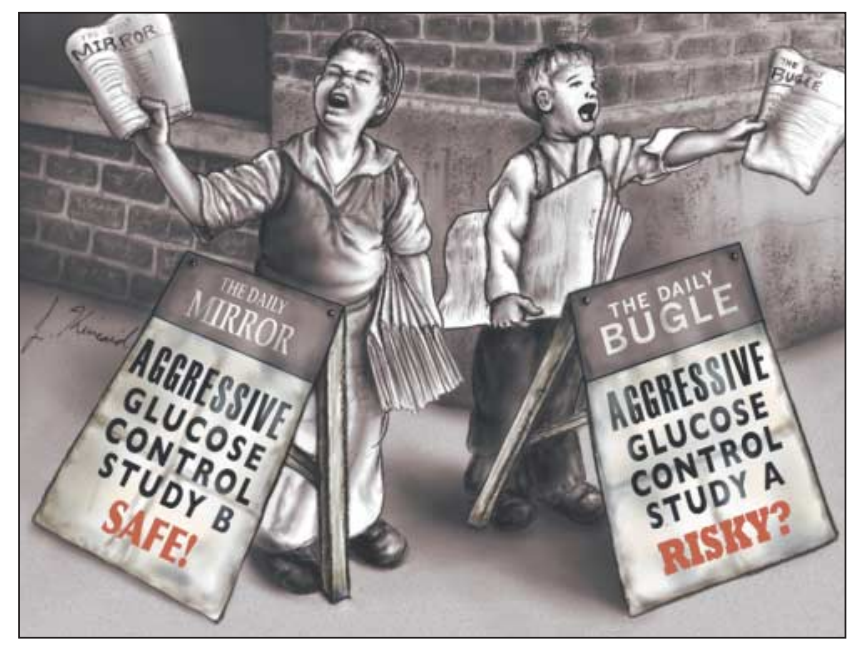

Contradictory findings from 2 studies that were announced through the news media have left physicians treating patients with diabetes concerned about the aggressive lowering of blood glucose to levels below those recommended in treatment guidelines. 